\title{
Square Waveguide Polarizer with Diagonally Located Irises for Ka-Band Antenna Systems
}

\author{
Stepan Piltyay \\ ${ }^{1}$ Department of Radio Engineering, National Technical University of Ukraine "Igor Sikorsky Kyiv Polytechnic Institute", Kyiv, Ukraine \\ Corresponding author: Stepan Piltyay (e-mail: crosspolar@ukr.net).
}

\begin{abstract}
This article presents the results of development and optimization of a new square waveguide polarizer with diagonally located corner square irises. The application of proposed geometrical modification of irises form and location instead of the standard wall-to-wall irises configuration allows to exclude typically used 45-degree twists between wideband waveguide polarizer and orthomode transducer of a dualpolarized antenna feed systems. In addition, a waveguide polarizer and polarization duplexer can be manufactured by milling technology as two single symmetrical details, which makes the proposed engineering solution reliable, simple for simulation, development and application. Suggested new polarizer design was developed for the operating satellite Ka-band. It contains 12 irises, which are symmetrically located in the diagonal corners of a square waveguide. Obtained optimal polarization converter provides excellent matching and polarization performance simultaneously. The maximum level of VSWR is less than 1.04 for both orthogonal polarizations of fundamental electromagnetic modes. The values of crosspolarization discrimination are higher than $32 \mathrm{~dB}$ in the operating Ka-band. Developed square waveguide polarizer with diagonally located irises can be applied in modern wideband satellite antennas and radar systems with dual-polarization operation.
\end{abstract}

INDEX TERMS microwave engineering, waveguide polarizer, iris polarizer, electromagnetic simulation, circular polarization, satellite antenna feeds, waveguide components, satellite information systems, radar.

\section{INTRODUCTION}

M ODERN radio engineering and telecommunication systems often provide simultaneous transmission and reception of information intended for multiple users in a single operating frequency bands. The occurring problem of distribution and allocation of information resources within licensed bands is especially relevant in satellite, mobile and radar systems [1-4]. In this context, the application of radio engineering systems, which provide operating at two orthogonal polarizations of electromagnetic waves within the same frequency band, becomes an effective and popular solution [5-7]. In large reflector antenna systems for satellite communications main polarization characteristics are determined by the microwave feed network [8]. Typically, it includes a corrugated horn [9-14], a waveguide polarization converter [15-19], a $45^{\circ}$ waveguide twist [7, 8] and a guidebased orthomode duplexer [20-24]. The dimensions of each specified component of a feed must be optimized for the required operating frequency band. In this case we obtain a satisfied dual-polarization performance of the whole reflector antenna system for satellite or space appliances.

The efficiency of polarizations conversion and discrimination in the waveguide antenna feed network are mainly determined by the electromagnetic characteristics of an applied guide polarizer [8]. In this regard, polarization transformer is a key waveguide component of an antenna feed system, which must be accurately simulated, optimized and manufactured with high precision. State-of-the-art designs of waveguide polarization converters are based on various types of discontinuity elements, which load a guide transmission line of a square, circular or coaxial cross section [25-34]. For example, irises-based polarizers and phase shifters are developed and optimized for satellite applications in [35-40]. Another designs of polarization converters apply posts and combinations of posts and irises for the obtaining of required matching and polarization performance [41-44]. In addition, several designs of waveguide polarizers and orthomode duplexers based on ridged [45-51] and septum structures [52-57] inside waveguides were presented.

Classically, the connection of a waveguide polarizer and an orthomode duplexer is performed at the $45^{\circ}$ angle by means of an additional waveguide twist with several stepped sections for matching improvement [7, 8]. Any additional passive waveguide component in an antenna feed system introduces reflection, noises, transmission losses and deteriorates overall cross-polarization discrimination.

In [58] L. A. Rud and K. S. Shpachenko suggested to apply diagonal ridges in a square waveguide to create a polarizer section with differential phase shift close to $90^{\circ}$. On one hand, such section of a square waveguide is simpler for 
manufacturing, because it does not require the milling of additional corrugations or diaphragms. On the other hand, for obtaining of good matching and adjustment in a moderately broad frequency band the authors of [58] required to apply additional iris. Besides, for the maximum levels of axial ratio of $1 \mathrm{~dB}$ and return losses better than $25 \mathrm{~dB}$ the fractional operating bandwidth was only $13 \%$, which is unacceptable for modern wideband satellite systems. For example, novel microwave feed systems and polarization processing units of Ka-band reflector antennas are developed for the frequency range of $17.7-22.2 \mathrm{GHz}$ with relative bandwidth of $23 \%$.

In [57] the authors demonstrated that similar operating bandwidth limitations occur in septum polarizers, which also are not based on a series of local discontinuities placed in a waveguide. It is well known that structures of waveguide polarizers, that are based on lumped discontinuities, allow radio engineers to overcome mentioned drawback of the polarization converters with conducting ridges or septums [59-61]. Among the practical designs with lumped elements it is worth to highlight polarizers with metal irises (or diaphragms) [62-65] and cylindrical metal posts [66, 67]. Waveguide polarization converters with irises provide broadening of the operating frequency range with simultaneous improvement of electromagnetic performance by increasing of the number of applied discontinuities [68].

Consequently, development and optimization of a new configuration of irises and waveguide polarizers based on them is an important problem of modern microwave antenna systems with dual polarization operation. This article is dedicated to solution of mentioned problem by introduction of a new concept of diagonally located irises, which provide effective performance in a wide operating frequency band combined with simple fabrication and the possibility of connection of a waveguide polarizer to an orthomode duplexer without a $45^{\circ}$ waveguide twist.

\section{STRUCTURE OF A SQUARE WAVEGUIDE POLARIZER WITH DIAGONALLY LOCATED IRISES}

The external view and inner configuration (with outer perfect electric conductor as a background material) of a suggested waveguide polarizer with diagonally located irises are demonstrated in Fig. 1(a) and (b), respectively. Developed microwave device is based on a square waveguide with the cross-sectional dimensions of $a \times a$ and length $L$. A milling technology is typical for the fabrication of waveguide iris polarizer designs. The device is milled from two identical metal bricks, which are then joined together. Fabricated by milling two metal details are also the same. Consequently, applied for the accurate electromagnetic analysis geometrical model must take into account round edges at the corners of irises. According to commercially available sizes of mills and the easiness of fabrication, the diameters of corner blends were chosen equal to $2 \mathrm{~mm}$.

Modern dual-polarization feed systems of large reflector antennas require low overall level of voltage standing wave ration. It can be achieved only in the case of excellent matching performance of each waveguide component of the applied feed network. Considered in this research polarizer is developed for the Ka-band 17.7-22.2 GHz. The fractional bandwidth of this satellite band exceeds $20 \%$. Obtained earlier in $[8,16]$ results have demonstrated that in order to provide efficient matching of a waveguide polarizer in such broadband frequency range a number of applied irises must be greater than 10. For optimization of square guide polarizer design and estimation of its electromagnetic characteristics in Ka-band a 12 irises-based structure has been selected.
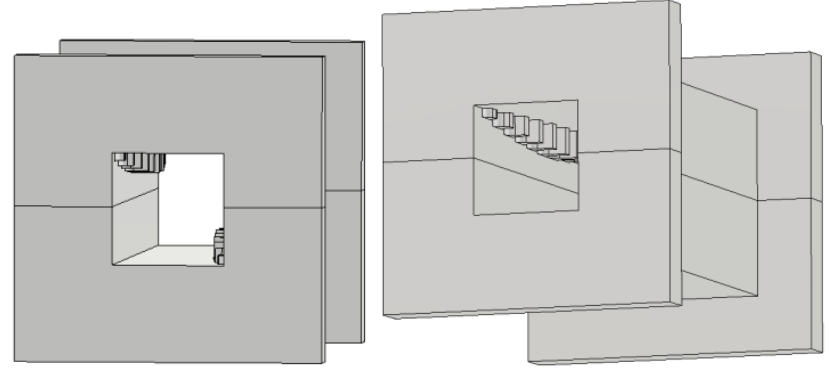

(a)

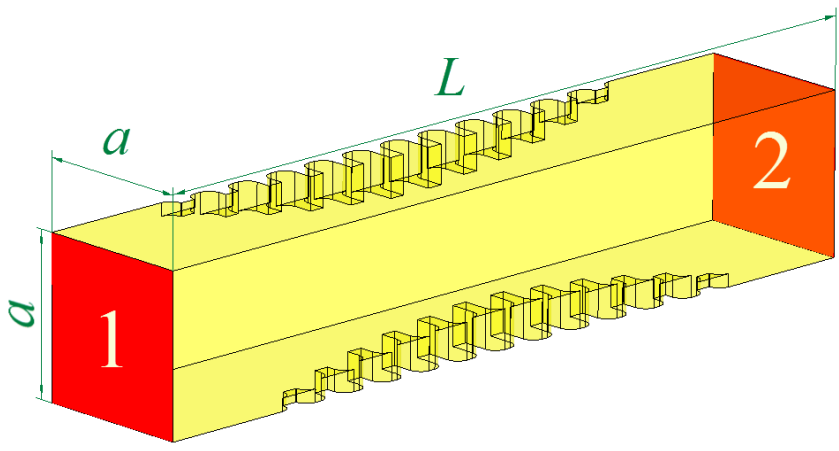

(b)

FIGURE 1. External view (a) and inner structure (b) of the developed square waveguide polarizer with diagonally located irises

\section{OPERATION PRINCIPLE OF A DEVELOPED SQUARE WAVEGUIDE IRIS POLARIZER FOR FUNDAMENTAL ELECTROMAGNETIC MODES}

In order to obtain electromagnetic mode's propagation in any waveguide the wavelength of excitation source must be less than the mode's cutoff wavelength [69]. Therefore, standard rectangular waveguides possess width of the broad wall, which in the whole operating frequency band must be greater than the half wavelength of fundamental TE 10 mode [70]. On the other hand, square waveguide is typically selected for development of dual-polarization antennas and microwave systems [71-74]. It possesses equal height and width of its side conducting walls. In this case the height and width are simultaneously greater than half wavelength (and, furthermore, than the quarter wavelength) of the propagating mode. Consequently, TE01 mode, which was below-cutoff in a rectangular waveguide, becomes simultaneously propagating with $\mathrm{TE}_{10}$ mode in a square waveguide. These two fundamental modes of a square 
waveguide are degenerative (i.e. they possess identical cutoff wavelengths and frequencies).

The main function of properly developed waveguide polarizer for receiving antenna system is to transform a circularly polarized fundamental electromagnetic guide mode into the one possessing linear polarization. In the case of simultaneous application of a waveguide polarizer with an orthomode duplexer the antenna feed network supports transformation and separation of two electromagnetic waves with orthogonal circular polarizations.

Let us consider fundamental TE electromagnetic mode with circular polarization, which propagates from an input port 1 to an output port 2 of a guide polarizer (Fig. 1(b)). This fundamental mode can be equivalently considered as a superposition of two fundamental TE modes, whose maximum field vectors are oriented along the diagonals of cross section of a square waveguide. Electric field vectors of this representation's modes are illustrated in Fig. 2. mode 1

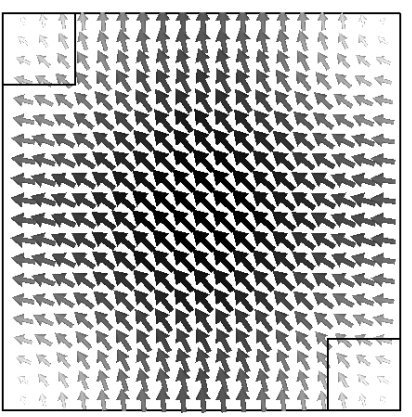

mode 2

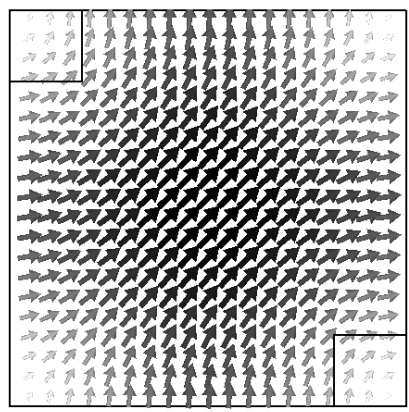

FIGURE 2. Electric field vectors of two orthogonal fundamental TE modes at ports of a square guide (sections of irises are highlighted for modes analysis)

As it is seen in Fig. 1 and 2, for one fundamental mode the electric field vectors will be concentrated between the corners of used diagonally located irises. In this case the irises will weakly influence the mode's propagation process, slightly reduce its phase velocity and introduce small additional phase shift. On the contrary, for another fundamental mode 2 the irises are located in that square waveguide regions, where the electric field is orthogonal to irises corners. In the regions of square irises edges the surface currents are concentrated and disturb high tension of transversal magnetic field of the mode 2. This results in strong influence of irises presence on the propagation of the second mode, for which the cutoff frequency and phase velocity increase. Therefore, by varying the geometrical configuration of the waveguide and irises the required differential phase shift close to $90^{\circ}$ can be easily obtained for the whole operating Ka-band. Effective improvement of overall matching of developed waveguide polarizer is achieved by the increment of number of applied irises.

At the input port 1 (Fig. 1(b)) of a waveguide polarizer in a receiving feed system two fundamental electromagnetic modes, whose electric fields are shown in Fig. 2, possess phase shift $\pm 90^{\circ}$ between them. Optimized structure of a waveguide polarizer introduces additional $90^{\circ}$ differential phase shift, that almost totally compensates the initial shift. Consequently, at the output port 2 (Fig. 1(b)) two orthogonal electromagnetic TE modes, whose electric field vectors are demonstrated in Fig. 2, become in-phase or antiphase ones. This leads to formation of two orthogonal $\mathrm{TE}_{10}$ and $\mathrm{TE}_{01}$ modes at the output port 2, which possess vertical and horizontal linear polarizations, respectively. Maximum in magnitude electric field vectors of these orthogonal fundamental modes is located in the center of a square waveguide and are oriented perpendicularly to its conducting sidewalls. After the propagation through the polarizer's structure, these resulting modes with horizontal and vertical linear polarizations can be effectively separated to isolated waveguide channels by an orthomode duplexer.

\section{DISPERSION CHARACTERISTICS OF A SQUARE WAVEGUIDE WITH DIAGONALLY LOADED CORNERS}

Let us theoretically analyze dispersion characteristics for the fundamental TE modes 1 and 2 of a square waveguide, which were presented in Fig. 2. As a result of the optimization of waveguide polarizer's structure for the operating Ka-band the values and ratios of its sizes were obtained. In particular, optimal inner transversal dimension of a square waveguide $a=0.87 \cdot \lambda_{0}$, average heights and widths of square corner irises $\langle h\rangle=0.153 \cdot \lambda_{0}$, total length of irises waveguide section $z=2.9 \cdot \lambda_{0}$, where $\lambda_{0}$ stands for the wavelength of electromagnetic wave in vacuum at the central frequency of the operating band $f_{0}$. Then, the cutoff frequency for the fundamental TE mode of a considered square waveguide $f_{\mathrm{c}}=\mathrm{c} /(2 a)=0.575 \cdot f_{0}$.

As a result of numerical solution of eigenmodes problem for a square waveguide with inner sizes $a \times a$, which is loaded by conducting ridges with sizes $\langle h\rangle \times\langle h\rangle$ in two opposite diagonal corners (Fig. 2), the cutoff frequencies of its two lower electromagnetic modes were obtained. The cutoff frequency for a fundamental TE mode with electric field configuration similar to the mode's 1 (Fig. 2) $f_{\mathrm{c} 1}=0.563 \cdot f_{0}$. For the TE mode with electric field structure similar to the mode's 2 (Fig. 2) $f_{\mathrm{c} 2}=0.641 \cdot f_{0}$.

The propagation constant of any mode in a guide, that is filled by air, depends on the frequency as follows $[69,70]$ :

$$
\beta(f)=\frac{2 \pi f}{\mathrm{c}} \sqrt{1-\left(\frac{f_{\mathrm{c}}}{f}\right)^{2}},
$$

where $\mathrm{c}$ designates the speed of light in the air.

The phase velocity of TE electromagnetic mode in a waveguide is expressed by the known formula $[69,70]$ :

$$
\mathrm{v}_{\mathrm{p}}(f)=\frac{\omega}{\beta(f)}=\frac{\mathrm{c}}{\sqrt{1-\left(\frac{f_{\mathrm{c}}}{f}\right)^{2}}} .
$$

Differential phase shift, which is introduced by the developed polarizer with diagonally located irises, can be approximately estimated as the difference of phases obtained by the modes 1 and 2 (Fig. 2) at the waveguide section with irises. The total path for surface currents consists of the total length of irises section and the sum of inner heights of all irises along their diagonals: $L_{\Sigma}=z+22 \sqrt{2}\langle h\rangle=7.66 \cdot \lambda_{0}$. The propagation constant for the mode 2 of a waveguide with irises or corrugations can be estimated as the average between the propagation 
constants of an unloaded square waveguide and a square waveguide, that is loaded by conducting ridges in corners:

$$
\beta_{\mathrm{m} 2}(f)=\frac{\beta_{2}(f)+\beta_{0}(f)}{2} .
$$

Consequently, introduced by the developed waveguide polarizer differential phase shift is as follows:

$$
\begin{gathered}
\Delta \varphi(f)=\beta_{1}(f) L_{\Sigma}-\beta_{\mathrm{m} 2}(f) L_{\Sigma}=\left[\beta_{1}(f)-\beta_{\mathrm{m} 2}(f)\right] L_{\Sigma}= \\
=\frac{2 \pi f L_{\Sigma}}{\mathrm{c}}\left[\sqrt{1-\left(\frac{f_{\mathrm{c} 1}}{f}\right)^{2}}-\frac{\sqrt{1-\left(\frac{f_{\mathrm{c} 2}}{f}\right)^{2}}+\sqrt{1-\left(\frac{f_{\mathrm{c}}}{f}\right)^{2}}}{2}\right] .
\end{gathered}
$$

Using the formula (1), dispersion diagrams were obtained for the two lowest electromagnetic modes of the considered square waveguide with $\left(\beta_{1}, \beta_{2}\right)$ and without $\left(\beta_{0}\right)$ conducting loadings in the corners of a square waveguide. Fig. 3-5 present the frequency dependences of propagation constants, phase velocities and differential phase shift in the frequency range from $0.5 f_{0}$ to $1.2 f_{0}$. The propagation constants and phase velocities of considered TE modes were normalized with respect to free space wave number at the center frequency and the speed of light, respectively.

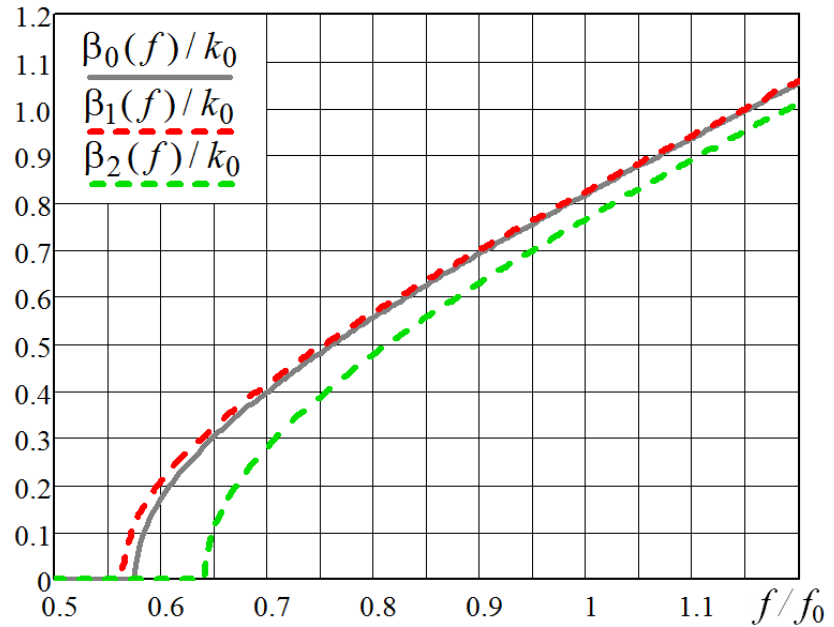

FIGURE 3. Dispersion diagrams for TE eigenmodes of a square waveguide with and without diagonally located square corner conducting irises

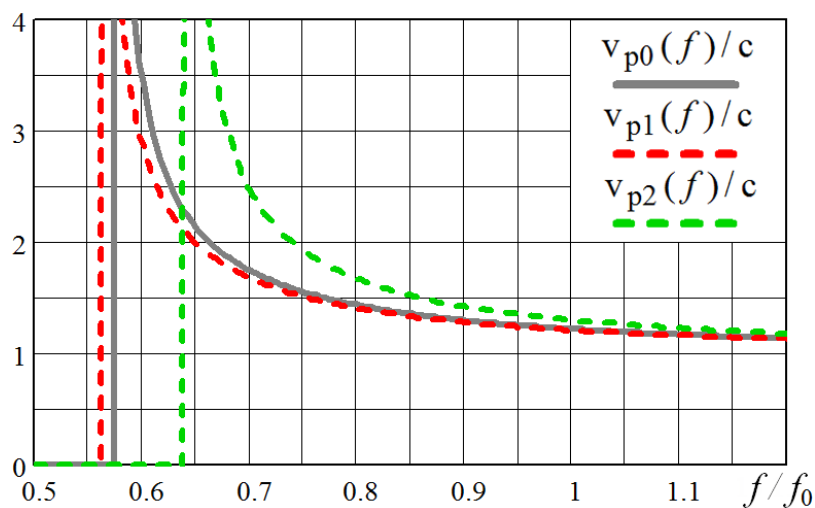

FIGURE 4. Phase velocities of TE eigenmodes of a square waveguide with and without diagonally located square corner conducting irises

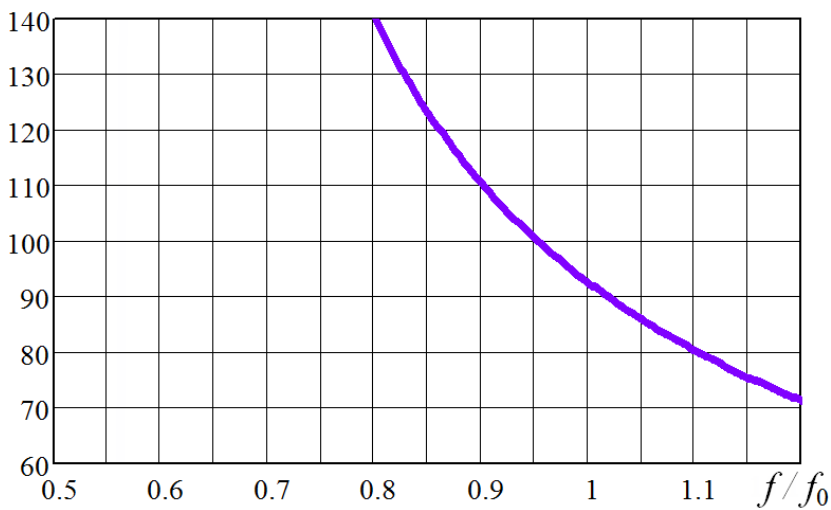

FIGURE 5. Output differential phase shift $\left({ }^{\circ}\right)$ between the modes 1 and 2

As can be seen in Fig. 5, calculated by a single-mode approximation differential phase shift deviates from the optimal parabolic-type behavior (Fig. 6). Besides, the numerical values of the shift vary from $80^{\circ}$ to $110^{\circ}$ in the $20 \%$ frequency range $0.9 f_{0}-1.1 f_{0}$. Obtained deviation of the differential phase shift from obtained numerically in the next section is caused by the neglecting of higher-order modes and boundary conditions at the conducting irises edges. Nevertheless, performed in this section analysis of eigenmodes and dispersion characteristics can be applied for fast initial estimation of waveguide iris polarizer's performance with its further optimization using more accurate numerical techniques.

\section{PHASE SHIFT, POLARIZATION AND MATCHING CHARACTERISTICS OF OPTIMIZED KA-BAND GUIDE POLARIZER WITH DIAGONALLY LOCATED IRISES}

In [75-78] the authors demonstrated numerical benefits, which are provided by the application of finite elements method in the frequency domain for the simulation of microwave waveguide polarizers. Therefore, mentioned method was also used in current research to perform the simulations of electromagnetic characteristics of a square waveguide polarizer with diagonally located irises. In [42] the authors have demonstrated effective and fast numerical performance of trust region method of optimization for tunable square waveguide iris-post polarizer operating in satellite Ku-band 10.7-12.8 GHz. Therefore, mentioned optimization technique is applied in current research to obtain required polarization characteristics of developed square waveguide polarizer with diagonally located irises for a higher Ka-band 17.7-22.2 GHz. All sizes of the inner structure of a waveguide polarizer, which is presented in Fig. 1(b), were varied during the optimization process of trust region method. The goal function of carried out optimization procedure consisted in obtaining of effective cross-polarization discrimination of a waveguide polarizer higher than $32 \mathrm{~dB}$.

A relatively compact design of a broadband waveguide iris polarizer has been obtained after the performed optimization. The inner cross-sectional dimensions of a square waveguide are $13.08 \times 13.08 \mathrm{~mm}^{2}$ and the total length $L=60 \mathrm{~mm}$, which equals to 4 wavelengths at the central frequency of operating Ka-band 17.7-22.2 GHz.

Obtained after the numerical optimization differential phase shift introduced by the developed square guide 
polarizer with diagonally located irises is shown in Fig. 6. It is clearly observed that the polarizer provides excellent phase characteristic of centered parabola type. In the whole operating frequency band the optimized differential phase shift of a polarizer totally falls within the range of $90^{\circ} \pm 2.9^{\circ}$.

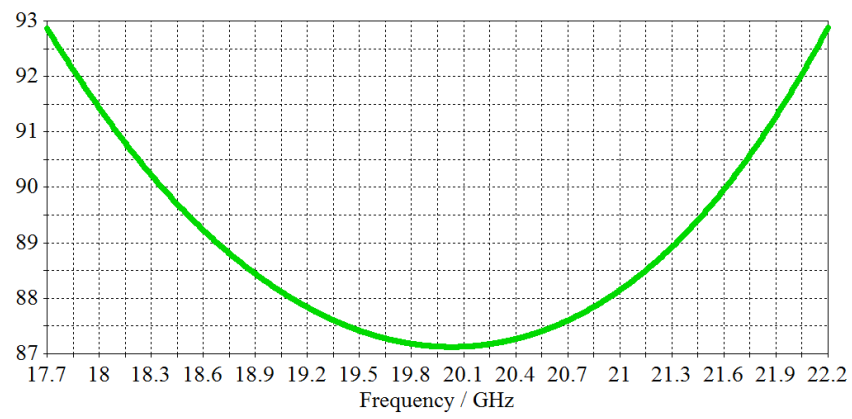

FIGURE 6. Differential phase shift $\left({ }^{\circ}\right)$ introduced by optimized guide polarizer

Polarization performance of a waveguide polarizer is frequently characterized by an axial ratio or a crosspolarization discrimination between orthogonal modes. Let us also considered these important characteristics for the optimized design of a square waveguide iris polarizer. They can be easily calculated using amplitudes of fundamental electromagnetic modes and phase shift between them at the output port using the known formulas [27, 28].

Fig. 7 presents the frequency dependence of axial ratio of the developed waveguide iris polarizer in the operating satellite Ka-band 17.7-22.2 GHz. It is seen that the axial ratio is less than $0.45 \mathrm{~dB}$ in the whole operating band.

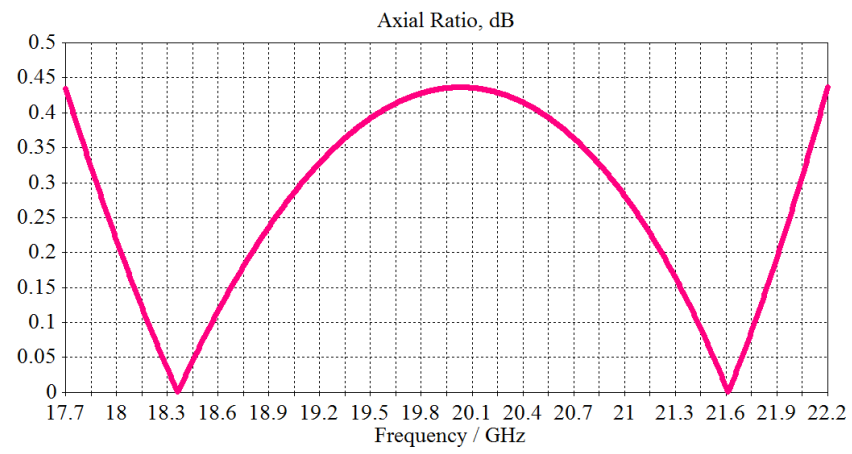

FIGURE 7. Axial ratio (in dB) of the optimized Ka-band waveguide polarizer

As one can observe in Fig. 7, the minimum levels of axial ratio, which are equal to $0 \mathrm{~dB}$, occur at the frequencies of $18.36 \mathrm{GHz}$ and $21.61 \mathrm{GHz}$. It is seen in Fig. 3 that at mentioned frequencies the differential phase shift of a polarizer is exactly equal to $90^{\circ}$. It was expected from the physical point of view, because the waveguide polarizer is a passive reciprocal device and it can be used for the transformation of a linearly polarized electromagnetic mode into a circularly polarized one, whose axial ratio is equal to $0 \mathrm{~dB}$ in the perfect case.

The undesired influence of independent signals, which are transmitted by the orthogonally polarized modes in satellite antenna feeds, is characterized by a crosspolarization discrimination (XPD). The dependence of XPD of a Ka-band waveguide polarizer with diagonally located irises on frequency is illustrated in Fig. 8.

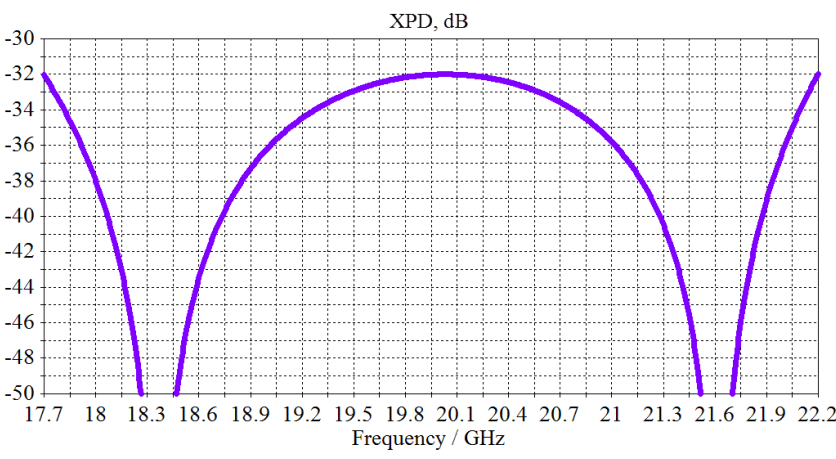

FIGURE 8. XPD (in dB) of the optimized Ka-band waveguide iris polarizer

It is seen in Fig. 8, that the optimized structure of developed waveguide iris polarizer provides XPD higher than $32 \mathrm{~dB}$ in the whole operating Ka-band 17.7-22.2 GHz. The perfect isolation between orthogonal modes occurs at the frequencies $18.36 \mathrm{GHz}$ and $21.61 \mathrm{GHz}$, which correspond to $90^{\circ}$ differential phase shift and to axial ratio equal to $0 \mathrm{~dB}$. Consequently, Fig. 8 additionally demonstrates that suggested structure of the waveguide iris polarizer can be effectively applied for the development of new dual-band feeds of modern reflector antennas for satellite communication systems.

Now let us consider the matching performance of optimized structure of developed waveguide polarizer with diagonally located irises. Matching is also an important characteristic of a waveguide polarizer, which determines the deterioration of its phase and polarization performance caused by multiple reflections from a corrugated horn and an orthomode duplexer [53]. Besides, high levels of polarizer's voltage standing wave ratio (greater than 1.5 ) lead to deterioration of its polarization characteristics. In the case of inefficient matching the axial ratio and XPD become dependent on the unequal magnitudes of fundamental electromagnetic modes at the output port of a waveguide polarizer $[27,28]$.

The dependences of waveguide polarizer's VSWR on frequency were also calculated using finite elements method in the frequency domain. These dependences in the Ka-band are shown in Fig. 9. Red and green curves correspond to the first and second fundamental electromagnetic modes with electric fields oriented along the diagonals of a square waveguide, respectively (Fig. 2).

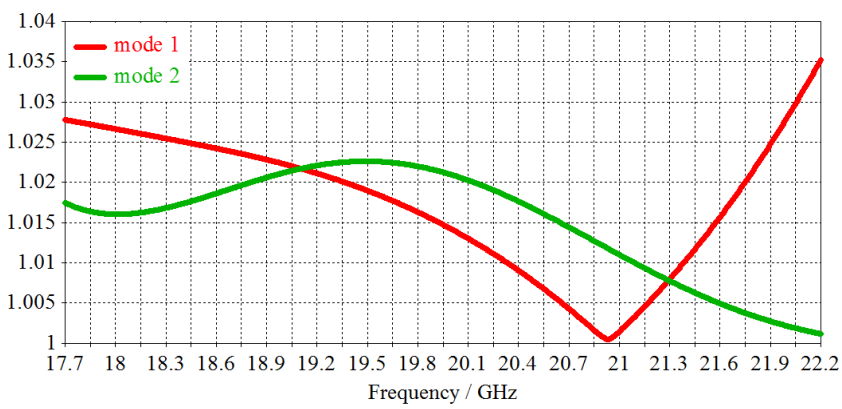

FIGURE 9. VSWR of the optimized waveguide iris polarizer for Ka-band

In Fig. 9 it is seen that VSWR is less than 1.04 for both orthogonal fundamental electromagnetic modes, which propagate in the developed structure of a waveguide 
polarizer with diagonally located irises. The extreme levels of reflection occur at the lowest and the highest frequencies of the operating Ka-band for the first fundamental mode with electric field concentrated between the corners of diagonally located irises (Fig. 2). Fast increase of VSWR at the highest frequency for this mode confirms its strong influence of irises on the process of its propagation and on its characteristics. On the whole, optimized design of developed waveguide polarizer with diagonally located irises provides excellent matching in the operating Ka-band 17.7-22.2 $\mathrm{GHz}$ for fundamental electromagnetic modes with any polarization type.

\section{CONCLUSIONS}

A new design of a broadband waveguide iris polarizer was developed and optimized in the research. The main peculiarity of the structure consists in the location of square-shaped irises in the corners of a square waveguide. This engineering solution allows to exclude a $45^{\circ}$ guide twist between a polarizer and an orthomode duplexer, which was required in all previously existent broadband antenna feed systems with dual-polarization operation.

In addition, developed microwave waveguide device can be fabricated with high accuracy from two metal bricks by the milling technology. This provides perfect inner contact of diagonally located irises with the square waveguide. Obtained two details are identical and can be easily joined together in a single reliable waveguide design.

Numerical simulations and optimization of waveguide polarizer's structure confirmed its possibility to provide excellent phase, polarization and matching characteristics simultaneously. A broadband square waveguide polarizer with diagonally located irises was developed for Ka-band 17.7-22.2 GHz, in which it provided differential phase shift of $90^{\circ} \pm 2.9^{\circ}$. Axial ratio of the optimized waveguide iris polarizer is less than $0.45 \mathrm{~dB}$ in the whole operating frequency band. XPD of the polarizer is higher than $32 \mathrm{~dB}$. VSWR is less than 1.04 in the whole operating Ka-band 17.7-22.2 GHz for any polarization type.

Therefore, developed new design of a square waveguide polarizer with diagonally located square-shaped irises can be widely applied in modern feeds of reflector antennas for satellite communication systems and radars, which operate in various frequency bands at two orthogonal circular polarizations simultaneously.

\section{REFERENCES}

[1] W. L. Stutzman, Polarization in Electromagnetic Systems. Norwood, MA, USA: Artech House, 2018.

[2] K. Chang, Encyclopedia of RF and Microwave Engineering. New Jersey, USA: John Wiley and Sons, 2005.

[3] A. Bulashenko et al., "New traffic model of M2M Technology in 5G wireless sensor networks", IEEE 2nd International Conference on Advanced Trends in Information Theory, Kyiv, Ukraine, November 2020, pp. 125-131. DOI: 10.1109/ATIT50783.2020.9349305.

[4] M. Saravanan and M.J.S. Rangachar, "Polarization reconfigurable square patch antenna for wireless communications", Advanced Electromagnetics, vol. 7, no. 4, pp. 103-108, September 2018. DOI: 10.107716/aem.v7i4.805.

[5] J. A. Ruiz-Cruz, M. M. Fahmi, S. A. Fouladi, and R. R. Mansour, "Waveguide antenna feeders with integrated reconfigurable dual circular polarization", IEEE Transactions on Microwave Theory and Techniques, vol. 59, no. 12, pp. 3365-3374, December 2011. DOI: 10.1109/TMTT.2011.2170581.

[6] F. F. Dubrovka and S. I. Piltyay, "A high performance ultrawideband orthomode transducer and a dual-polarized quad-ridged horn antenna based on it", VIII International Conference on Antenna Theory and Techniques (ICATT), Kyiv, Ukraine, September 2011, pp. 176-178. DOI: 10.1109/ICATT.2011.6170737.

[7] O. A. Peverini, G. Virone et al., "Development of passive microwave antenna-feed systems for wide-band dual-polarisation receivers", IET Microwaves, Antennas and Propagation, vol. 5, no. 8, pp. 1008 1015, June 2011. DOI: 10.1049/iet-map.2010.0340.

[8] S. I. Piltyay, "High performance extended C-band 3.4-4.8 GHz dual circular polarization feed system", XI International Conference on Antenna Theory and Techniques (ICATT), Kyiv, Ukraine, May 2017, pp. 284-287. DOI: 10.1109/ICATT.2017.7972644.

[9] P.J.B. Clarricoats, A.D. Olver, Corrugated Horns for Microwave Antennas. London, UK: Peter Peregrinus Ltd., 1984.

[10] B. Du, E. Kai-Ning Yung, K.-Z. Yang, and W.-J. Zhang, "Wide-band linearly or circularly polarized monopulse tracking corrugated horn", IEEE Transactions on Antennas and Propagation, vol. 50, no. 2, pp. 192-197. February 2002. DOI: 10.1109/8.997994.

[11] M. Bray, "Dual X/Ka-band corrugated feed horn for deep space telecommunications", IEEE International Symposium on Antennas and Propagation (APSURSI), Fajardo, Puerto Rico, June 2016. DOI: 10.1109/APS.2016.7696481.

[12] A.D. Olver., P.J.B. Clarricoats et al., Microwave Horns and Feeds. London: Institution of Electrical Engineers, 1994.

[13] S. Li, Z. Liu, W. Cao, X. Yu et al., "Design of a Ku-band corrugated horn with good-symmetrical pattern", 12th International Symposium on Antennas, Propagation and EM Theory (ISAPE), Hangzhou, China, December 2018. DOI: 10.1109/ISAPE.2018.8634016.

[14] F. Dubrovka et al., "Circularly polarised X-band H11- and H21modes antenna feed for monopulse autotracking ground station", IEEE Ukrainian Microwave Week (UkrMW), Kharkiv, Ukraine, September 2020, pp. 196-202. DOI: 10.1109/UkrMW49653.2020.9252600.

[15] G. Virone, et al., "Optimum-iris-set concept for waveguide polarizers", IEEE Microwave and Wireless Components Letters, vol. 17, no. 3, pp. 202-204, 2007. DOI: 10.1109/LMWC.2006.890474.

[16] G. Virone, et al., "Combined-phase-shift waveguide polarizer", IEEE Microwave and Wireless Comp. Letters, vol. 18, no. 8, pp. 509-511, August 2008. DOI: 10.1109/LMWC.2008.2001005.

[17] G. Bertin, et al., "Full-wave design and optimization of circular waveguide polarizers with elliptical irises", IEEE Transactions on Microwave Theory and Techniques, vol. 50, no. 4, pp. 1077-1083, April 2002. DOI: 10.1109/22.993409.

[18] J. A. Ruiz-Cruz, M. M. Fahmi, M. Daneshmand, and R. R. Mansour, "Compact reconfigurable waveguide circular polarizer," IEEE Microwave Symposium Digest (MTT), Baltimore, USA, June 2011, pp. 1-4. DOI: 10.1109/MWSYM.2011.5972872.

[19] G. Bertin et al., "Analysis and design of circular waveguide polarizers with elliptical irises", 30th European Microwave Conference, Paris, France, October 2000, pp. 1-4. DOI: 10.1109/EUMA.2000.338646.

[20] M. Kamikura, et al., "Development of a submillimeter double-ridged waveguide ortho-mode transducer (OMT) for the $385-500 \mathrm{GHz}$ band", Journal of Infrared Millimeter and Terahertz Waves, vol. 31, no. 6, pp. 697-707, March 2010. DOI: 10.1007/s10762-010-9632-1.

[21] F. F. Dubrovka and S. I. Piltyay, "Novel high performance coherent dual-wideband orthomode transducer for coaxial horn feeds", $X I$ International Conference on Antenna Theory and Techniques (ICATT), Kyiv, Ukraine, May 2017, pp. 277-280. DOI: 10.1109/ICATT.2017.7972642.

[22] G. Virone, O. A. Peverini, M. Lumia, M. Z. Farooqui, G. Addamo, and R. Tascone, "W-Band orthomode transducer for dense focalplane clusters", IEEE Microwave and Wireless Components Letters, vol. 25, no. 2, pp. 85-87, February 2015. DOI: 10.1109/LMWC.2014.2373638. 
[23] J. A. Ruiz-Cruz, J. R. Montejo-Garai, C. A. Leal-Sevillano, and J. M. Rebollar, "Orthomode transducers with folded doublesymmetry junctions for broadband and compact antenna feeds", IEEE Transactions on Antennas and Propagation, vol. 66, no. 3 , pp. 1160-1168, March 2018. DOI: 10.1109/TAP.2018.2794364.

[24] E. Menargues et al., "Four-port broadband orthomode transducer enabling arbitrary interelement spacing”, IEEE Transactions on Microwave Theory and Techniques, vol. 66, no. 12, pp. 5521-5530, November 2018. DOI: 10.1109/TMTT.2018.2878208.

[25] S. I. Piltyay, A. V. Bulashenko, and I. V. Demchenko, "Waveguide iris polarizers for Ku-band satellite antenna feeds", Journal of Nanoand Electronic Physics, vol. 12, no. 5, pp. 05024-1-05024-5, October 2020. DOI: $10.21272 /$ jnep.12(5).05024.

[26] O. Sushko et al., "Symmetrically fed 1-10 GHz log-periodic dipole antenna array feed for reflector antennas", IEEE Ukrainian Microwave Week (UkrMW), Kharkiv, Ukraine, September 2020 pp. 222-225. DOI: 10.1109/UkrMW49653.2020.9252778.

[27] S. I. Piltyay, A. V. Bulashenko, and I. V. Demchenko, "Analytical synthesis of waveguide iris polarizers", Telecommunications and Radio Engineering, vol. 79, no. 18, pp. 1579-1597, November 2020. DOI: 10.1615/TelecomRadEng.v79.i18.10.

[28] A. V. Bulashenko, S. I. Piltyay, and I. V. Demchenko, "Wave matrix technique for waveguide iris polarizers simulation. Theory", Journal of Nano- and Electronic Physics, vol. 12, no. 6, pp. 06026-1-060265, December 2020. DOI: 10.21272/jnep.12(6).06026.

[29] V. Naydenko et al., "Evolution of radiopulses radiated by Hertz's dipole in vacuum", 12-th International Conference on Mathematical Methods in Electromagnetic Theory (MMET), Odesa, Ukraine, July 2008, pp. 294-297. DOI: 10.1109/MMET.2008.4580972.

[30] S. Piltyay, "Circular waveguide polarizer for weather radars and satellite information systems," Journal of Microwaves, Optoelectronics and Electromagnetic Applications, vol. 20, no. 3, September 2021.

[31] F. F. Dubrovka et al., "Eigenmodes analysis of sectoral coaxial ridged waveguides by transverse field-matching technique. Part 1 Theory", Visnyk NTUU KPI Seriia - Radiotekhnika, Radioaparatobuduvannia, vol. 54, pp.13-23. 2013. DOI: 10.20535/RADAP.2013.54.13-23

[32] F. F. Dubrovka et al., "Eigenmodes analysis of sectoral coaxial ridged waveguides by transverse field-matching technique. Part 2. Numerical results", Visnyk NTUU KPI Seriia - Radiotekhnika, Radioaparatobuduvannia, vol. 55, pp. 13-23. 2013. DOI: 10.20535/RADAP.2013.55.13-23.

[33] S. I. Piltyay, "Enhanced C-band coaxial orthomode transducer", Visnyk NTUU KPI Seriia - Radiotekhnika, Radioaparatobuduvannia, vol. 58, pp. 27-34, September 2014. DOI: 10.20535/RADAP.2014.58.27-34

[34] F. F. Dubrovka and S. I. Piltyay, "A novel wideband coaxial polarizer", IX International Conference on Antenna Theory and Techniques (ICATT), Odesa, Ukraine, September 2013, pp. 473-474. DOI: 10.1109/ICATT.2013.6650816.

[35] S.I. Piltyay, O.Yu. Sushko, A.V. Bulashenko, and I.V. Demchenko, "Compact Ku-band iris polarizers for satellite telecommunication systems", Telecommunications and Radio Engineering, vol. 79, no. 19, pp. 1673-1690, 2020. DOI: 10.1615/TelecomRadEng.v79.i19.10.

[36] A. Bulashenko, S. Piltyay, and I. Demchenko, "Analytical technique for iris polarizers development", IEEE International Conference on Problems of Infocommunications. Science and Technology (PIC S\&T), Kharkiv, Ukraine, October 2020, pp. 593-598. DOI: 10.1109/PICST51311.2020.9467981.

[37] S. Piltyay, A. Bulashenko, and I. Demchenko, "Compact polarizers for satellite information systems", IEEE International Conference on Problems of Infocommunications. Science and Technology (PIC S\&T), Kharkiv, Ukraine, October 2020, pp. 557-562. DOI: 10.1109/PICST51311.2020.9467889.

[38] A. Bulashenko, S. Piltyay, and I. Demchenko, "Energy efficiency of the D2D direct connection system in 5G networks", IEEE International Conference on Problems of Infocommunications.
Science and Technology (PIC S\&T), Kharkiv, Ukraine, October 2020, pp. 537-542. DOI: 10.1109/PICST51311.2020.9468035.

[39] S. Piltyay, A. Bulashenko, and I. Demchenko, "Wireless sensor network connectivity in heterogeneous $5 \mathrm{G}$ mobile systems", IEEE International Conference on Problems of Infocommunications. Science and Technology (PIC S\&T), Kharkiv, Ukraine, October 2020, pp. 625-630. DOI: 10.1109/PICST51311.2020.9468073.

[40] A. V. Bulashenko and S. I. Piltyay, "Equivalent microwave circuit technique for waveguide iris polarizers development", Visnyk NTUU KPI Seriia - Radiotekhnika, Radioaparatobuduvannia, vol. 83, pp. 17-28. 2020. DOI: 10.20535/RADAP.2020.83.17-28.

[41] B. Subbarao, V. F. Fusco, “Compact coaxial-fed CP polarizer”, IEEE Antennas and Wireless Propagation Letters, vol. 3, pp. 145-147, April 2004. DOI: 10.1109/LAWP.2004.831084.

[42] S. Piltyay, A. Bulashenko, O. Sushko, O. Bulashenko, and I. Demchenko, "Analytical modeling and optimization of new $\mathrm{Ku}$ band tunable square waveguide iris-post polarizer," International Journal of Numerical Modelling: Electronic Networks, Devices and Fields, vol. 34, no. 5, pp. 1-27, 2021. DOI: 10.1002/JNM.2890.

[43] A. Bulashenko, et al., "Mathematical modeling of iris-post sections for waveguide filters, phase shifters and polarizers", IEEE 2nd International Conference on Advanced Trends in Information Theory (IEEE ATIT), Kyiv, Ukraine, November 2020, pp. 330-336. DOI: 10.1109/ATIT50783.2020.9349321.

[44] S. Piltyay, A. Bulashenko, H. Kushnir, and O. Bulashenko, "New tunable iris-post square waveguide polarizers for satellite information systems", IEEE 2nd International Conference on Advanced Trends in Information Theory (IEEE ATIT), Kyiv, Ukraine, November 2020, pp. 342-348. DOI: 10.1109/ATIT50783.2020.9349357.

[45] T.-L. Zhang, Z.-H. Yan, L. Chen, and F.-F. Fan, "Design of broadband orthomode transducer based on double ridged waveguide", Proceeding of International Conference on Microwave and Millimeter Wave Tech. (ICMMT 2010), Chengdu, China, May 2010, pp. 765-768. DOI: 10.1109/ICMMT.2010.5525061.

[46] F. F. Dubrovka et al., "Eigenmodes of sectoral coaxial ridged waveguides", Radioelectronics and Communications Systems, vol. 55, no. 6, pp. 239-247. June 2012. DOI: $10.3103 / \mathrm{S} 0735272712060015$.

[47] F. F. Dubrovka et al., "Eigenmodes of coaxial quad-ridged waveguides. Theory", Radioelectronics and Communications Systems, vol. 57, no. 1, pp. 1-30. January 2014. DOI: $10.3103 / \mathrm{S} 0735272714010014$.

[48] F. F. Dubrovka et al., "Eigenmodes of coaxial quad-ridged waveguides. Numerical results", Radioelectronics and Communications Systems, vol. 57, no. 2, pp. 59-69. February 2014. DOI: $10.3103 / \mathrm{S} 0735272714020010$.

[49] S. I. Piltyay, "Numerically effective basis functions in integral equation technique for sectoral coaxial ridged waveguides", 14-th International Conference on Mathematical Methods in Electromagnetic Theory (MMET), Kyiv, Ukraine, August 2012, pp. 492-495. DOI: 10.1109/MMET.2012.6331195.

[50] F. F. Dubrovka et al., "Prediction of eigenmodes cutoff frequencies of sectoral coaxial ridged waveguides", XI International Conference on Modern Problems of Radio Engineering, Telecommunications and Computer Science. Slavske, Ukraine, February 2012, pp. 191.

[51] F. F. Dubrovka, et al., "Electrodynamics boundary problem solution for sectoral coaxial ridged waveguides by integral equation technique", Radioelectronics and Communications Systems, vol. 55, no. 5, pp. 191-203. May 2012. DOI: 10.3103/S0735272712050019.

[52] B. Deutschmann and A. F. Jacob, "Broadband septum polarizer with triangular common port," IEEE Transactions on Microwave Theory and Techniques, vol. 68, no. 2, pp. 693-700, 2020. DOI: 10.1109/TMTT.2019.2951138.

[53] F. Dubrovka et al., "Compact X-band stepped-thickness septum polarizer", IEEE Ukrainian Microwave Week (UkrMW), Kharkiv, Ukraine, September 2020, pp. 135-138. DOI: 10.1109/UkrMW49653.2020.9252583.

[54] C. A. Leal-Sevillano et al., "A $225 \mathrm{GHz}$ circular polarization waveguide duplexer based on a septum orthomode transducer 
polarizer," IEEE Trans. on Terahertz Science and Technology, vol. 3 no. 5, pp. 574-583, Sept. 2013. DOI: 10.1109/TTHZ.2013.2264317.

[55] J.-C. Angevain and N. J. G. Fonseca, "Waveguide septum polarizer shaped with Legendre polynomials," 11th European Conference on Antennas and Propagation (EUCAP), Paris, France, March 2017, pp. 2286-2290. DOI: 10.23919/EuCAP.2017.7928324.

[56] N. Nikolic et al., "A septum polarizer with integrated square to circular tapered waveguide transition", IEEE International Symposium on Antennas and Propagation \& USNC/URSI National Radio Science Meeting, Boston, USA, July 2018, pp. 725-726. DOI: 10.1109/APUSNCURSINRSM.2018.8608909.

[57] F. F. Dubrovka et al., "Optimum septum polarizer design for various fractional bandwidths," Radioelectronics and Communications Systems, vol. 63, no. 1, pp. 15-23, January 2020. DOI: $10.3103 / \mathrm{S} 0735272720010021$.

[58] L. A. Rud and K.S. Shpachenko, "Polarizers on a segment of square waveguide with diagonal ridges and adjustment iris," Radioelectronics and Communications Systems, vol. 55, no. 10, pp. 458-463, 2012. DOI: 10.3103/S0735272712100044.

[59] V. Shuliak et al., "Modern microwave polarizers and their electromagnetic characteristics", IEEE 3rd Ukraine Conference on Electrical and Computer Engineering, Lviv, Ukraine, August 2021.

[60] O. Bykovskyi et al., "Synthesis of waveguide diaphragm polarizers using wave matrix approach", IEEE 3rd Ukraine Conference on Electrical and Computer Engineering, Lviv, Ukraine, August 2021.

[61] Y. Herhil et al., "Characteristic impedances of rectangular and circular waveguides for fundamental modes", IEEE 3rd Ukraine Conference on Electrical and Computer Engineering, Lviv, Ukraine, August 2021

[62] I. Fesyuk et al., "Waveguide polarizer for radar systems of $2 \mathrm{~cm}$ wavelength range", IEEE 3rd Ukraine Conference on Electrical and Computer Engineering, Lviv, Ukraine, August 2021.

[63] H. Kushnir et al., "Multiple reflections method for diaphragms polarizer development", IEEE International Conference on Problems of Infocommunications. Science and Technology (PIC S\&T), Kharkiv, Ukraine, 2021.

[64] Y. Herhil et al., "Electromagnetic waves propagation in ferrimagnetic materials and their application for designing of nonreciprocal microwave devices", IEEE International Conference on Problems of Infocommunications. Science and Technology (PIC S\&T), Kharkiv, Ukraine, 2021

[65] V. Shuliak et al., "Waveguide polarizer of reflector antenna feeds for satellite communication systems", IEEE International Conference on Problems of Infocommunications. Science and Technology (PIC S\&T), Kharkiv, Ukraine, 2021.

[66] A. Polishchuk et al., "Compact posts-based waveguide polarizer for satellite communications and radar systems", IEEE 3rd Ukraine Conference on Electrical and Computer Engineering, Lviv, Ukraine, August 2021.
[67] Y. Kalinichenko et al., "Adjustable iris-post waveguide polarizer for Ku-band satellite uplink systems", IEEE 3rd Ukraine Conference on Electrical and Computer Engineering, Lviv, Ukraine, August 2021.

[68] S. Piltyay, A. Bulashenko, I. Fesyuk, and O. Bulashenko, "Comparative analysis of compact satellite polarizers based on a guide with diaphragms", Advanced Electromagnetics, vol. 10, no. 2, p. 44-55, 2021. DOI: 10.7716/aem.v10i2.1713.

[69] R. E. Collin. Fondations for Microwave Engineering. New Jersey: John Wiley and Sons, 2001

[70] D. M. Pozar. Microwave Engineering. Hoboken, New Jersey: John Wiley and Sons, 2012.

[71] F. F. Dubrovka et al., "Analytical and numerical method of constructive synthesis of optimal polarizers based on three irises in square waveguide", Radioelectronics and Communications Systems, vol. 64, no 4, pp. 204-215, April 2021. DOI: 10.3103/S073527272104004X.

[72] S. Piltyay, A. Bulashenko, V. Shuliak, and O. Bulashenko, "Electromagnetic simulation of new tunable guide polarizers with diaphragms and pins", Advanced Electromagnetics, vol. 10, no. 3, 2021. DOI: 10.7716/aem.v10i3.1737.

[73] A.V. Bulashenko, S.I. Piltyay, I.I. Dikhtyaruk, and O.V. Bulashenko, "Technique of mathematical synthesis of waveguide iris polarizers", Journal of Nano- and Electronic Physics, vol. 13, no. 5, pp. 050211-05021-5, 2021

[74] A. V. Bulashenko, S. I. Piltyay, and I. V. Demchenko, "Wave matrix technique for waveguide iris polarizers simulation. Numerical results", Journal of Nano- and Electronic Physics, vol. 13, no. 5, pp. 05017-1-05017-5, 2021.

[75] S. Piltyay, A. Bulashenko, Y. Herhil, and O. Bulashenko, "FDTD and FEM simulation of microwave waveguide polarizers", IEEE 2nd International Conference on Advanced Trends in Information Theory (IEEE ATIT), Kyiv, Ukraine, November 2020, pp. 357-363. DOI: 10.1109/ATIT50783.2020.9349339.

[76] O. Bykovskyi et al., "Accuracy and agreement of FDTD, FEM and wave matrix methods for the electromagnetic simulation of waveguide polarizers", IEEE International Conference on Problems of Infocommunications. Science and Technology (PIC S\&T), Kharkiv, Ukraine, 2021.

[77] A. V. Bulashenko, et al., "Waveguide polarizer for radar and satellite systems", Visnyk NTUU KPI Seriia - Radiotekhnika Radioaparatobuduvannia, vol. 86, September 2021. DOI: 10.20535/RADAP.2021.86.

[78] S. I. Piltyay, A. V. Bulashenko, and Y. Y. Herhil, "Numerical performance of FEM and FDTD methods for the simulation of waveguide polarizers", Visnyk NTUU KPI Seriia - Radiotekhnika Radioaparatobuduvannia, vol. 84, pp. 11-21. March 2021. DOI: 10.20535/RADAP.2021.84.11-21. 